\title{
Study on the Solvent Effect on Radical Polymerization of Polystyrene Macromonomer
}

\author{
Kiyoharu Tsutsumi, Yasuhisa Tsukahara, ${ }^{*}{ }^{\dagger}$ and Yoshio OKamoto \\ Department of Applied Chemistry, Faculty of Engineering, \\ Nagoya University, Furo-cho, Chikusa-ku, \\ Nagoya 464-01, Japan \\ ${ }^{\dagger}$ Department of Materials Science, \\ Kyoto Institute of Technology, Matsugasaki, Sakyo-ku, \\ Kyoto 606, Japan
}

(Received November 30, 1992)

\begin{abstract}
Radical polymerizations of polystyrene macromonomers having a methacryloyl end group, $M_{n}$ of which are 2900 and 12400 , were carried out in benzene and methylcyclohexane to study the solvent effect on the polymerization behavior. Radical polymerizations were done at $60^{\circ} \mathrm{C}$ with $\mathrm{AIBN}$ as an initiator under homogeneous condition. Degree of polymerization (DP), polymerization rate $\left(R_{\mathrm{p}}\right)$ and concentration of propagating radical $\left(\left[\mathrm{M}^{*}\right]\right)$ were evaluated by a gel permeation chromatography (GPC) equipped with a laser light scattering detector and an electron spin resonance (ESR) spectroscopy. Intrinsic viscosity $([\eta])$ of macromonomers and formed poly(macromonomer)s in benzene and methylcyclohexane were also measured at the polymerization temperature. It was found that both $D P$ and $R_{\mathrm{p}}$ in methylcyclohexane were larger than those in benzene irrespective of the molecular weight of the macromonomer. From $D P, R_{\mathrm{p}}$, and $\left[\mathrm{M}^{*}\right]$, propagation rate constant $\left(k_{\mathrm{p}}\right)$ and termination rate constant $\left(k_{\mathrm{t}}\right)$ were evaluated. $k_{\mathrm{t}}$ in methylcyclohexane was smaller than that in benzene, while $k_{\mathrm{p}}$ in methylcyclohexane was nearly equal to, or slightly larger than, that in benzene. These results were considered in terms of the change in the segment density around the propagating radical site by the solvent nature.
\end{abstract}

KEY WORDS Macromonomer / Radical Polymerization / Solvent Effect /

Diffusion Control Effect / Segment Density / Intrinsic Viscosity /

Since the polymerization product of a macromonomer has a specific multi-branched structure, the segment density around the propagating radical site is much different from that of the corresponding linear polymer. This influences the polymerization behavior of macromonomers. ${ }^{1-3}$ The conformation and the segment density of polymer molecules are also influenced by solvent. In some cases, aggregates or micelles are formed in a preferential solvent. Therefore, the nature of solvent affects on polymerization behavior of macromonomers. ${ }^{4-8}$

Recently, we reported the radical polymer- ization behavior of polystyrene macromonomers having a methacryloyl end group and a vinylbenzyl end group in benzene by an ESR measurement. It was found that the propagating radical had a long life time enough to give the ESR spectrum of the propagating radical. ${ }^{2}$ However, we did not observe the ESR spectrum of the propagating radical of MMA in the equimolar mixture of MMA and inert polystyrene of the same molecular weight as the macromonomer, although polymerization was done under the same viscosity and monomer concentration. These results indicate that the specific multi-branched structure

\footnotetext{
* To whom correspondence should be addressed.
} 
around the active site of propagating radical as well as the viscosity greatly affect the polymerization behavior of the macromonomers.

In this study, we have investigated the influence of solvent on the polymerization behavior of polystyrene macromonomers.

\section{EXPERIMENTAL}

\section{Materials}

Polystyrene macromonomers having a methacryloyl end group (MA-PSt) were prepared by the same procedure as described in a previous paper. ${ }^{1}$ The characteristics of the macromonomers are shown in Table I. Benzene (good solvent) and methylcyclohexane $\left(T_{\theta}=\right.$ $70^{\circ} \mathrm{C}$, moderately poor solvent) as polymerization solvents were dried on $\mathrm{Na}$ wire and distilled under nitrogen after removal of the stabilizer. AIBN was used after recrystallization from methanol at $40^{\circ} \mathrm{C}$.

\section{Polymerization of Macromonomers}

Polymerization of the macromonomers was carried out in benzene or methylcyclohexane with AIBN at $60^{\circ} \mathrm{C}$. The mixture of macromonomer, solvent, and initiator was equally divided into sixteen parts and placed in glass ampules. Each ampule was degassed and sealed under vacuum. These ampules were placed in the thermostated bath regulated at $60^{\circ} \mathrm{C}$, and then polymerizations were carried out for various times. All of polymerization solutions were homogeneous throughout the polymerization reaction. After polymerization, the ampule was cooled to $-78^{\circ} \mathrm{C}$, and the polymerization product was taken out and precipitated into methanol and then freezedried with benzene.

\section{Evaluation of Molecular Weight and Polym- erization Rate}

The molecular weights of poly(macromonomer)s $\left(M_{w}\right)$ and the polymerization rates $\left(R_{\mathrm{p}}\right)$ were determined by using a GPC apparatus equipped with a low-angle laser light scattering detector in addition to the conventional RI and UV detectors (LS-GPC). ${ }^{1}$ The GPC apparatus used was a high-speed liquid chromatograph, HLC802A of Tosoh Co., Ltd., equipped with an LS-8 (LS detector, He-Ne laser with a detection angle of $5^{\circ}$ ) and UV-8 (UV detector, $254 \mathrm{~nm}$ wavelength, $D_{2}$ lump), which was operated with Tosoh $\mathrm{G} 2000 \mathrm{H}+\mathrm{G} 4000 \mathrm{H}+$ $\mathrm{G} 6000 \mathrm{H}$ columns at $25^{\circ} \mathrm{C}$ on toluene or $\mathrm{G} 3000 \mathrm{H}+\mathrm{G} 5000 \mathrm{H}$ columns at $30^{\circ} \mathrm{C}$ on $\mathrm{CHCl}_{3}$. The $M_{w}$ 's of poly(macromonomer)s were determined from the peak area ratio of LS response to RI response of polymerization

Table I. Characterizations of polystyrene macromonomers

\begin{tabular}{ccccc}
\hline Code $^{\mathrm{a}}$ & $M_{w}{ }^{\mathrm{b}}$ & $M_{w} / M_{n}{ }^{\mathrm{b}}$ & $\begin{array}{c}\text { End } \\
\text { functionality }\end{array}$ & $\begin{array}{c}\text { Maximum }_{\text {conversion }^{\mathrm{d}}} \\
\text { MA-PSt2900 }\end{array}$ \\
MA-PSt12400 & 3100 & 1.06 & 0.93 & 0.93 \\
\hline
\end{tabular}

a Chemical structure of MA-PSt macromonomers is

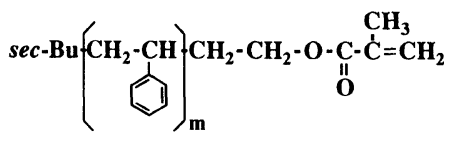

Numeral in the sample code represents number average molecular weight of the macromonomer.

b Determined by GPC using standard polystyrene calibration curve.

c Determined by $500 \mathrm{MHz}^{1} \mathrm{H}$ NMR in $\mathrm{CDCl}_{3}$ at $60^{\circ} \mathrm{C}$.

${ }^{d}$ Maximum conversion of the macromonomer in copolymerizations with MMA in benzene for $48 \mathrm{~h}$ at $60^{\circ} \mathrm{C}$. Initiator is AIBN. 
products in LS-GPC. The degree of conversion was determined from the ratio of the peak area of unreacted macromonomer to the total peak area of the polymerization product in GPC charts taken with UV detector.

\section{ESR Measurements}

The mixture of macromonomer, solvent and initiator was placed in an ESR sample tube (diameter $5 \mathrm{~mm}$, length $180 \mathrm{~mm}$ ) with a syringe, degassed and then sealed under vacuum. ESR spectra were taken at $60^{\circ} \mathrm{C}$ during polymerization. ESR measurements were carried out with a JEOL RE-1X X-band spectrometer with $100 \mathrm{kHz}$ modulation. ${ }^{2}$ The spectra were recorded with a PC9801RX personal computer connected to the spectrometer. The concentrations of the propagating radical $\left[\mathrm{M}^{*}\right]$ were calculated by double integration of the signal and comparison of the signal intensity with that from the standard $\left(5.0 \times 10^{-6}-1.0 \times 10^{-5}\right.$ $\mathrm{moll}^{-1}$ of diphenylpicrylhydrazyl (DPPH) in benzene). The signal of DPPH was also used as a $g$ value standard. The magnetic field sweep was calibrated with the splitting constant of $M_{n}{ }^{2+}$. Sample after ESR measurement at $60^{\circ} \mathrm{C}$ was cooled to $-78^{\circ} \mathrm{C}$, and the polymerization product was taken out and freeze-dried with benzene to evaluate $M_{w}$ and $R_{\mathrm{p}}$ by GPC.

\section{Intrinsic Viscosity}

Intrinsic viscosities of the macromonomer and the formed poly(macromonomer) at $60^{\circ} \mathrm{C}$ in benzene and methylcyclohexane were measured by an Ubbelohde viscometer. The poly(macromonomer)s for viscosity measurements were purified to remove the unreacted macromonomer by the repeated fractional precipitations from benzene solution to petroleum ether for MA-PSt2900 and $17: 10(\mathrm{v} / \mathrm{v})$ mixture of petroleum ether and cyclohexane for MA-PSt12400.

\section{RESULTS AND DISCUSSION}

The GPC curves of polymerization products of MA-PSt12400 at $[\mathrm{M}]=1.1 \times 10^{-2} \mathrm{moll}^{-1}$ in benzene and methylcyclohexane are shown in Figures 1(a) and (b). The large peak in the low molecular weight side corresponds to the unreacted macromonomer and the small peak at the high molecular weight side corresponds to the formed poly(macromonomer). In this case, the polymerization time was $6 \mathrm{~h}$, and the conversion in methylcyclohexane is $23 \%$ and that in benzene is $8.3 \%$. Thus, conversion in methylcyclohexane is larger than that in benzene. The peak position of the poly(macromonomer) in methylcyclohexane locates at higher molecular weight compared with that in benzene. The relative peak area of the poly(macromonomer) detected by LS to that of RI in methylcyclohexane is much larger than that in benzene.

In Figure 2, DPS of the polymerization products of MA-PSt12400 are plotted as a function of $[\mathrm{M}]$ for benzene and methylcyclohexane. All the polymerizations were carried out with $[\mathrm{I}]=8.2 \times 10^{-3} \mathrm{moll}^{-1}$ for $24 \mathrm{~h}$. It is seen that $D P$ of the poly(macromonomer)s increases with increase of $[\mathrm{M}]$ as already reported. $^{1,3}$ It is seen again that $D P$ in methylcyclohexane is larger than that in benzene at the same [M].

Figure 3 shows the time-conversion curve and the time- $D P$ curve for the polymerization of MA-PSt12400 at [M] $=1.1 \times 10^{-2} \mathrm{moll}^{-1}$ and $[\mathrm{I}]=8.2 \times 10^{-3} \mathrm{moll}^{-1}$. It should be noted here that polymerization systems in methylcyclohexane as well as in benzene were entirely homogeneous during polymerization, although methylcyclohexane is a moderately poor solvent for polystyrene at $60^{\circ} \mathrm{C}$. The chain transfer constant to benzene is reported $0.075 \times 10^{-4}$ and that to methylcyclohexane is $0.195 \times 10^{-4}$ in solution polymerization of MMA at $80^{\circ} \mathrm{C}^{9}$ The difference of chain transfer constant is small and negligible.

$D P$ of poly(macromonomer) is around 5 in benzene while around 15 in methylcyclohexane. The value is almost constant during polymerization in both solvents. $R_{\mathrm{p}}$ calculated from 

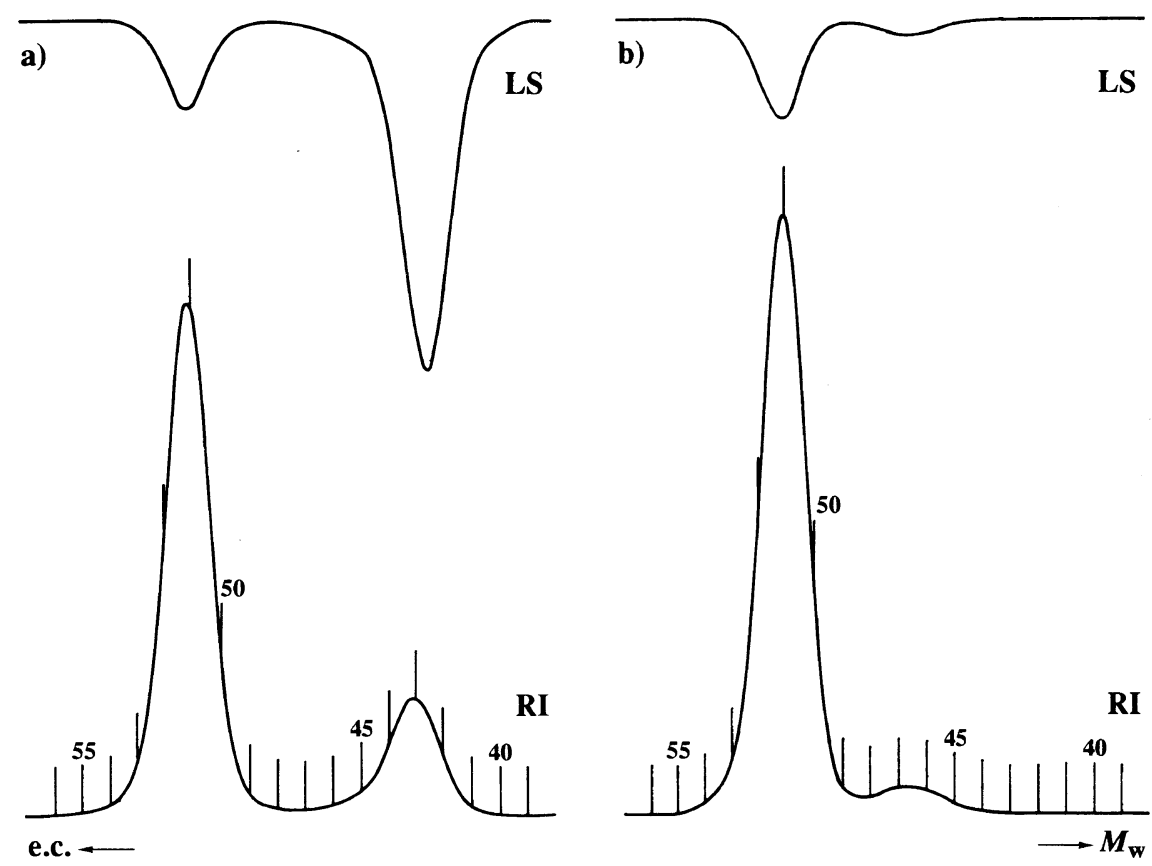

Figure 1. Comparison of GPC curves of the polymerization products of MA-PSt12400 in methylcyclohexane (a) and benzene (b) under the same polymerization conditions. Polymerizations were carried out at $60^{\circ} \mathrm{C}$ for $6 \mathrm{~h}$. $[\mathrm{M}]=1.1 \times 10^{-2} \mathrm{moll}^{-1}$. $[\mathrm{I}]=8.2 \times 10^{-3} \mathrm{moll}^{-1}$. The right peak in each chart corresponds to the produced poly(MA-PSt12400), and the left peak corresponds to the unreacted MAPSt 12400 .

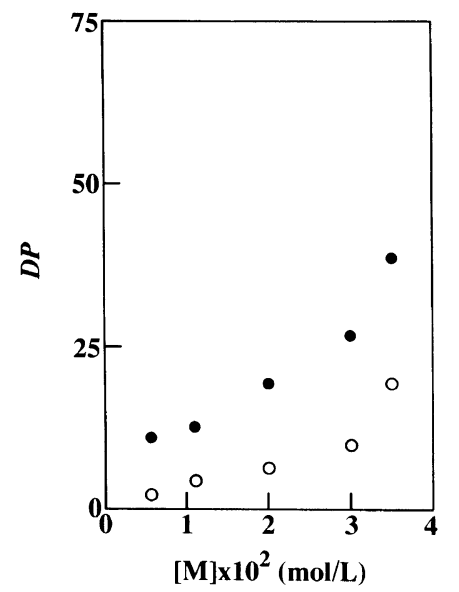

Figure 2. Comparison of DP versus $[\mathrm{M}]$ plots of poly(macromonomer)s for the polymerization of MA-PSt12400 in methylcyclohexane (closed symbol) and benzene (open symbol) with AIBN at $60^{\circ} \mathrm{C}$ for $24 \mathrm{~h}$.

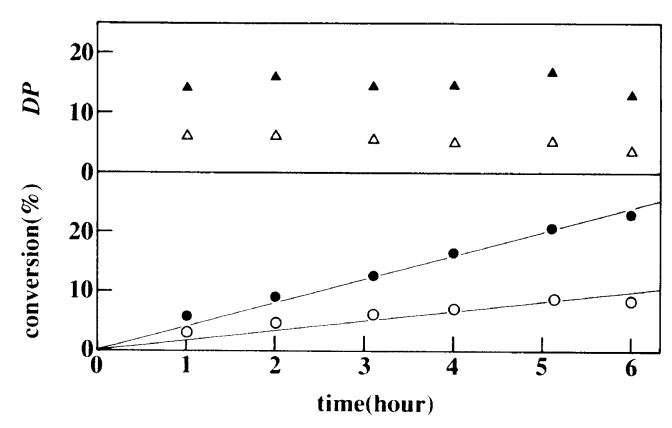

Figure 3. Comparison of conversion and DP versus polymerization time plots for the polymerization of MAPSt 12400 in methylcyclohexane (closed symbol) and benzene (open symbol) with AIBN at $60^{\circ} \mathrm{C}$. $[\mathrm{M}]=1.1 \times 10^{-2}$ $\mathrm{moll}^{-1},[\mathrm{I}]=8.2 \times 10^{-3} \mathrm{moll}^{-1}$.

the initial slope of time-conversion curve is larger in methylcyclohexane than that in benzene. $R_{\mathrm{p}}$ calculated from Figure 3 is $5.1 \times 10^{-8} \mathrm{moll}^{-1} \mathrm{~s}^{-1}$ in benzene and $1.1 \times$ 
$10^{-7} \mathrm{moll}^{-1} \mathrm{~s}^{-1}$ in methylcyclohexane. Table II summarizes the values of $D P$ and $R_{\mathrm{p}}$ for the polymerizations of MA-PSt2900 and MAPSt12400.

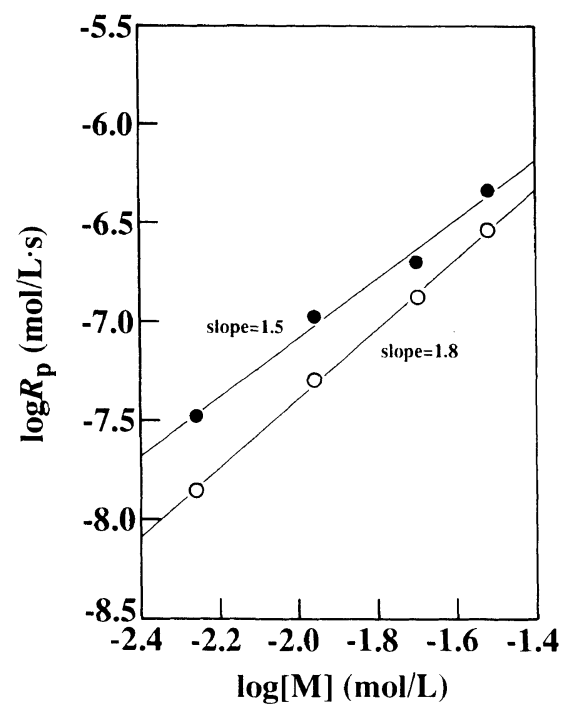

Figure 4. Comparison of $\log -\log$ plots of $R_{\mathrm{p}}$ versus [M] for the polymerization of MA-PSt12400 in methylcyclohexane (closed symbol) and benzene (open symbol). [I] = $8.2 \times 10^{-1} \mathrm{moll}^{-1}$.
Figure 4 shows $\log -\log$ plots of $R_{\mathrm{p}}$ versus [M] of MA-PSt12400. It is seen that $\log R_{\mathrm{p}}$ increases almost linearly with $\log [\mathrm{M}]$. It is seen again that $R_{\mathrm{p}}$ in methylcyclohexane is larger than that in benzene in this macromonomer concentration region. The apparent kinetic order of $R_{\mathrm{p}}$ with respect to [M] is 1.8 in benzene and 1.5 in methylcyclohexane. The difference of $R_{\mathrm{p}}$ between these solvents with increasing of monomer concentration decreased because the solvent effect on polymerization decreases with decreasing of solvent fraction.

Intrinsic viscosity $[\eta]$ is expressed by Flory-Fox equation, ${ }^{10}$

$$
[\eta] M=\Phi\left\langle S^{2}\right\rangle^{3 / 2}
$$

where $\left\langle S^{2}\right\rangle, M$ and $\Phi$ are the mean square radius of gyration, molecular weight and Flory's universal constant, respectively. This equation means that $[\eta] M$ is proportional to $\left\langle S^{2}\right\rangle^{3 / 2} .^{11}$ Table III shows $[\eta]$ and $[\eta] M$ of macromonomers and poly(macromonomer)s at $60^{\circ} \mathrm{C}$. In all cases, $[\eta] M$ in methylcyclohexane is smaller than that in benzene, showing that the molecular dimensions of both poly-

Table II. Effect of solvent on degree of polymerization $D P$, polymerization rate $R_{\mathrm{p}}$ and concentration of propagating radical $\left[\mathrm{M}^{*}\right]$ for polymerization of MA-PSt2900 and MA-PSt $12400^{\mathrm{a}}$

\begin{tabular}{|c|c|c|c|c|c|}
\hline \multirow{2}{*}{ Macromonomer } & \multirow{2}{*}{ Solvent } & {$[\mathrm{M}]^{\mathrm{b}}$} & \multirow{2}{*}{$D P^{\mathrm{c}}$} & \multirow{2}{*}{$\frac{R_{\mathrm{p}} \times 10^{7}}{\mathrm{moll}^{-1} \mathrm{~s}^{-1}}$} & \multirow{2}{*}{$\frac{\left[\mathrm{M}^{*}\right] \times 10^{7}}{\mathrm{moll}^{-1}}$} \\
\hline & & $\mathrm{moll}^{-1}$ & & & \\
\hline \multirow{4}{*}{ MA-PSt2900 } & $\mathrm{MCH}^{\mathrm{d}}$ & $3.0 \times 10^{-2}$ & 14 & 4.4 & 6.0 \\
\hline & & $1.1 \times 10^{-2}$ & 5.8 & 0.72 & 2.5 \\
\hline & $\mathbf{B z} \mathbf{z}^{\mathbf{e}}$ & $3.0 \times 10^{-2}$ & 4.0 & 1.9 & 3.4 \\
\hline & & $1.1 \times 10^{-2}$ & 2.0 & 0.28 & 1.4 \\
\hline \multirow{4}{*}{ MA-PSt 12400} & $\mathrm{MCH}^{\mathrm{d}}$ & $3.0 \times 10^{-2}$ & 27 & 4.6 & 7.1 \\
\hline & & $1.1 \times 10^{-2}$ & 13 & 1.1 & 3.7 \\
\hline & $\mathbf{B z}^{\mathbf{e}}$ & $3.0 \times 10^{-2}$ & 9.8 & 2.9 & 5.0 \\
\hline & & $1.1 \times 10^{-2}$ & 4.4 & 0.51 & 2.5 \\
\hline
\end{tabular}

a Polymerizations were carried out at $60^{\circ} \mathrm{C}$ with $\mathrm{AIBN}$. [I] $=8.2 \times 10^{-3} \mathrm{moll}^{-1}$.

b Not corrected with the end functionality.

\& Determined by GPC using a light scattering detector.

d Methylcyclohexane.

e Benzene. 
Table III. Intrinsic viscosity of macromonomers and poly(macromonomer)s at $60^{\circ} \mathrm{C}$ in methylcyclohexane and benzene

\begin{tabular}{|c|c|c|c|c|}
\hline \multirow{3}{*}{ Sample } & \multicolumn{2}{|c|}{ Methylcyclohexane } & \multicolumn{2}{|c|}{ Benzene } \\
\hline & {$[\eta]$} & {$[\eta] M_{w}$} & {$[\eta]$} & {$[\eta] M_{w}$} \\
\hline & $100 \mathrm{mlg}^{-1}$ & $100 \mathrm{ml} \mathrm{mol}^{-1}$ & $100 \mathrm{mlg}^{-1}$ & $100 \mathrm{ml} \mathrm{mol}^{-1}$ \\
\hline MA-PSt2900 & 0.0388 & 120 & 0.0395 & 120 \\
\hline Poly(MA-PSt2900) & 0.0624 & 1100 & 0.0794 & 1400 \\
\hline MA-PSt 12400 & 0.0695 & 910 & 0.0858 & 1120 \\
\hline Poly(MA-PSt12400) b & 0.0874 & 12200 & 0.1761 & 24700 \\
\hline
\end{tabular}

${ }^{\mathrm{a}} M_{w}=1.76 \times 10^{4} ; D P=5.68 ; M_{w} / M_{n}=1.35$.

b $M_{w}=1.40 \times 10^{5} ; D P=10.7 ; M_{w} / M_{n}=1.83$.

(macromonomer)s and macromonomers in the poor solvent is smaller, thus, of higher segment density than those in the good solvent. Especially, $[\eta] M$ of the poly(MA-PSt12400) with high molecular weight in methylcyclohexane greatly differs from that in benzene, while the difference in $[\eta] M$ of the poly(MAPSt2900) in both solvents are small.

The radical concentrations $\left[\mathrm{M}^{*}\right]$ determined from ESR spectrum at particular feed concentrations are shown in Table II together with $D P$ and $R_{\mathrm{p}}$. It is seen that $\left[\mathrm{M}^{*}\right] \mathrm{s}$ in methylcyclohexane are larger than those in benzene.

From measurement of $\left[\mathrm{M}^{*}\right]$ by ESR, the propagation rate constant, $k_{\mathrm{p}}$, and the termination rate constant, $k_{\mathrm{t}}$ can be estimated by using eq 2 and 3 with $R_{\mathrm{p}}$ and $D P$ values in Table II.

$$
\begin{aligned}
& k_{\mathrm{p}}=R_{\mathrm{p}} /[\mathrm{M}]\left[\mathrm{M}^{*}\right] \\
& k_{\mathrm{t}}=R_{\mathrm{p}} / 2 D P\left[\mathrm{M}^{*}\right]^{2}
\end{aligned}
$$

$k_{\mathrm{p}}, \quad k_{\mathrm{t}}$, and $k_{\mathrm{p}} / k_{\mathrm{t}}^{1 / 2}$, thus estimated, are summerized in Table IV. Since $k_{\mathrm{p}}$ and $k_{\mathrm{t}}$ of MMA are $5151 \mathrm{~mol}^{-1} \mathrm{~s}^{-1}$ and $2.55 \times 10^{-7} 1$ $\mathrm{mol}^{-1} \mathrm{~s}^{-1}$, respectively, ${ }^{12} k_{\mathrm{p}}$ and $k_{\mathrm{t}}$ of the macromonomers are much smaller than those of MMA as reported previously. ${ }^{3}$

In Table IV, $k_{\mathrm{p}}$ values are almost constant irrespectively of $[\mathrm{M}]$ and the molecular weight of the macromonomer. On the other hand, $k_{\mathrm{t}}$ values decrease drastically with increase of $[\mathrm{M}]$ and increase of the molecular weight of the macromonomer. These results indicate that the propagation reaction is essentially an activation controlled reaction and almost independent on [M] and $M_{n}$ of macromonomer. In contrast to this, the termination reaction rate decreases with increase of solution viscosity, thus dominated by the diffusion-control effect. The values of $k_{\mathrm{p}}$ in benzene in Table IV are consistent with those of MA-PSt4400 in previous paper. ${ }^{3}$

It is seen that $k_{\mathrm{p}}$ in methylcyclohexane is nearly equal to, or slightly larger than, that in benzene, while $k_{\mathrm{t}}$ in methylcyclohexane is smaller than that in benzene. Thus, the ratio $k_{\mathrm{p}} / k_{\mathrm{t}}{ }^{1 / 2}$ in methylcyclohexane becomes much larger than that in benzene, resulting to a larger $R_{\mathrm{p}}$ in methylcyclohexane than in benzene. The slightly larger values of $k_{\mathrm{p}}$ in Table IV in methylcyclohexane than in benzene might be partially ascribed to the difference in the local segment density around the propagating radical site or the difference in the interaction between the radical site and the solvent. However, the reason is not clear at present.

For a diffusion-controlled reaction like the bimolecular termination of radical polymerization, the rate constant should be inversely proportional to the solvent viscosity $\left(\eta_{0}\right) .{ }^{13,14}$ 
Table IV. Comparison of rate constants ${ }^{a}$ for propagation and termination and those for termination reduced by solvent viscosity ${ }^{b}$ in benzene and methylcyclohexane

\begin{tabular}{|c|c|c|c|c|c|}
\hline \multirow{2}{*}{ Solvent } & & \multicolumn{2}{|c|}{$\begin{array}{l}\text { MA-PSt } 2900 \\
{[\mathrm{M}] / \mathrm{moll}^{-1}}\end{array}$} & \multicolumn{2}{|c|}{$\begin{array}{c}\text { MA-PSt } 12400 \\
{[\mathrm{M}] / \mathrm{moll}^{-1}}\end{array}$} \\
\hline & & $1.1 \times 10^{-2}$ & $3.0 \times 10^{-2}$ & $1.1 \times 10^{-2}$ & $3.0 \times 10^{-2}$ \\
\hline \multirow[t]{4}{*}{$\mathrm{MCH}^{\mathrm{c}}$} & $k_{\mathrm{p}}\left(1 \mathrm{~mol}^{-1} \mathrm{~s}^{-1}\right)$ & 26 & 24 & 26 & 22 \\
\hline & $k_{\mathrm{t}}\left(\mathrm{lmol}^{-1} \mathrm{~s}^{-1}\right)$ & 100000 & 45000 & 31000 & 17000 \\
\hline & $k_{\mathrm{p}} / k_{\mathrm{t}}^{1 / 2}$ & 0.083 & 0.11 & 0.15 & 0.17 \\
\hline & $k_{\mathrm{t}} \cdot \eta_{0}$ & 540000 & 240000 & 160000 & 93000 \\
\hline \multirow[t]{4}{*}{$B z^{d}$} & $k_{\mathrm{p}}\left(1 \mathrm{~mol}^{-1} \mathrm{~s}^{-1}\right)$ & 18 & 19 & 19 & 19 \\
\hline & $k_{\mathrm{t}}\left(1 \mathrm{~mol}^{-1} \mathrm{~s}^{-1}\right)$ & 350000 & 210000 & 95000 & 58000 \\
\hline & $k_{\mathrm{p}} / k_{\mathrm{t}}^{1 / 2}$ & 0.030 & 0.041 & 0.061 & 0.079 \\
\hline & $k_{\mathrm{t}} \cdot \eta_{0}$ & 1400000 & 820000 & 380000 & 230000 \\
\hline
\end{tabular}

a Calculated from the eq 2,3 , see the text.

b Solvent viscosity at $60^{\circ} \mathrm{C}$ are the data from ref 23 . $\left(\eta_{0}=5.37 \mathrm{~m}\right.$ poise for methylcyclohexane, $\eta_{0}=4.00 \mathrm{~m}$ poise for benzene.)

c Methylcyclohexane.

d Benzene.

Table IV shows the values of the products of the termination rate constants and the solvent viscosity. It is seen that $k_{\mathrm{t}} \cdot \eta_{0}$ in methylcyclohexane is still smaller than those in benzene. Thus, this tendency is derived from the difference in segment density caused by the difference in solvent nature.

There are several studies about the effect of solvent on the termination reaction in polymerization reactions of small monomer and other polymer-polymer reactions. ${ }^{15-22} \mathrm{Ca}$ meron studied on the termination rate constant $\left(k_{t}\right)$ for the polymerization ${ }^{17}$ of MMA. They reported that $k_{\mathrm{t}}$ in the poor solvent was smaller than that in the monomer solution when $D P$ of PMMA was larger than $3.5 \times 10^{3}$. Horie and Mita studied on the rate constants for quenching of phosphorescence $\left(k_{\mathrm{q}}\right)$ of polystyrylbenzil by polystyrylanthracene. ${ }^{18}$ They reported that the reduced rate constant $k_{\mathrm{q}} \eta_{\mathrm{o}} / T$ ( $\eta_{0}$ is solvent viscosity and $T$ is temperature) in poor solvent was smaller than that in good solvent when $D P$ of polystyrene was larger than a particular value of $10 .{ }^{3}$ While, $k_{\mathrm{q}} \eta_{0} / T$ in good solvent was larger than that in poor solvent when $D P$ of polystyrene was smaller than $10 .^{3}$
These results indicate that the effect of thermodynamic repulsion between polymer segments (thermodynamic excluded volume effect) in poor solvent is smaller than that in good solvent. This makes the approach between polymer reaction species more easy. However, for high molecular weight reaction species, the effect of topological hindrance of polymer chain for the diffusion becomes more important (kinetic excluded volume effect), which is stronger in poor solvent than that in good solvent. Thus, the termination rate in poor solvent is smaller than that in good solvent.

In conclusion, the propagation reaction seems to be hardly affected by the concentration and the molecular weight of macromonomer, and thus, the propagation reaction is almost entirely dominated by the activation control step. Thus, the effect of solvent on $k_{\mathrm{p}}$ is small. However, the termination reaction, which is much faster reaction than the propagation reaction, is strongly affected by the concentration, molecular weight and the solvent nature. Therefore, the effect of solvent on the polymerization of the macromonomer 


\section{K. Tsutsumi, Y. Tsukahara, and Y. OKamoto}

comes solely from the termination reaction through solvent-dependent, diffusion-control effect.

\section{REFERENCES AND NOTES}

1. Y. Tsukahara, K. Mizuno, A. Segawa, and Y. Yamashita, Macromolecules, 22, 1546 (1989).

2. Y. Tsukahara, K. Tsutsumi, Y. Yamashita, and S. Shimada, Macromolecules, 22, 2869 (1989).

3. Y. Tsukahara, K. Tsutsumi, Y. Yamashita, and S. Shimada, Macromolecules, 23, 5201 (1990).

4. K. Ito, K. Hashimura, and S. Itsuno, Macromolecules, 24, 3977 (1991).

5. K. Ito and H. Kobayashi, Polym. J., 24, 199 (1992).

6. K. Ishizu, K. Shimomura, and T. Fukutomi, $J$. Polym. Sci., A, Polym. Chem., 29, 923 (1991).

7. M. Niwa, M. Akahori, and S. Nishizawa, $J$. Macromol. Sci.-Chem., A24, 1423 (1987).

8. J. P. Kennedy and M. Hiza, J. Polym. Sci., Polym. Chem. Ed., 21, 1033 (1983).

9. J. Brandrup and E. H. Immergut, "Polymer Handbook," 3rd ed, Wiley-Interscience, New York, N.Y., 1989.

10. P. J. Flory, "Principles of Polymer Chemistry," Cornell Univ. Press, Ithaca, N.Y., 1953.

11. $\Phi$ is an universal constant for linear polymers but reported to be dependent slightly on the branching structure in branched polymers. The clear dependence of $\Phi$ on the polymer structure is not given at present. See J. Roover, P. M. Topoloski, J. Polym. Sci., Polym. Phys., 18, 1907 (1980).

12. G. Odian, "Principles of Polymerization" 3rd ed, Wiley-Interseience, New York, N.Y., 1991.

13. A. M. North, Quart. Rev., 20, 421 (1966).

14. K. Horie, I. Mita, and H. Kambe, Polym. J., 4, 341 (1973).

15. H. Morawetz, J.-R. Cho, and P. J. Gans, Macromolecules, 6, 624 (1973).

16. J.-R. Cho and H. Morawetz, Macromolecules, 6, 628 (1973).

17. G. G. Cameron and J. Cameron, Polymer, 14, 107 (1973).

18. K. Horie and I. Mita, Macromolecules, 11, 1175 (1978).

19. I. Mita and K. Horie, J. Macromol. Sci., Rev. Macromol. Chem. Phys., C27(1), 91 (1987).

20. A. Okamoto, Y. Shimanuki, and I. Mita, Eur. Polym. J., 18, 545 (1982).

21. A. Okamoto, K. Toyoshima, and I. Mita, Eur. Polym. J., 19, 341 (1983).

22. M. S. Veeravalli and S. L. Rosen, J. Polym. Sci., B, Polym. Phys., 28, 775 (1990).

23. J. A. Riddick and W. B. Bunger, "Organic Solvents," 4th ed, Wiley-Interscience, New York, N.Y., 1986. 